\title{
Are we missing opportunities? Physiotherapy and physical activity promotion: a cross-sectional survey
}

\author{
Nicole Freene ${ }^{*} \mathbb{D}$, Sophie Cools and Bernie Bissett
}

\begin{abstract}
Background: Physical activity (PA) promotion in healthcare is an important strategy for increasing PA levels. Physiotherapists are well-positioned to promote PA, however no studies have investigated PA promotion by physiotherapists Australia-wide.

Methods: An online survey of practicing Australian physiotherapists was conducted to investigate knowledge of the Australian Physical Activity and Sedentary Behaviour (PASB) guidelines and factors associated with increased promotion frequency. Participants were asked to state the PASB guidelines and a 4-component scoring system was used to measure knowledge. Multivariate logistic regression analysis was conducted to assess factors associated with frequency of promotion.

Results: 257 Australian physiotherapists completed the survey. Only 10\% were able to accurately state the PASB guidelines and 54\% reported promoting PA to 10 or more patients per month. Males were nearly three times more likely than females to promote PA to 10 or more patients per month (OR 2.68, 95\% Cl 1.25-5.74). Those who lacked counselling skills and felt PA promotion wouldn't change their patients' behaviour were much less likely to promote PA.

Conclusion: Australian physiotherapists have poor knowledge of the Australian PASB guidelines and infrequently promote PA. Education and training in PA counselling and behaviour change strategies is indicated to enhance PA promotion by Australian physiotherapists.
\end{abstract}

Keywords: Physical activity, Health promotion, Survey

\section{Background}

The World Confederation of Physical Therapists states that physiotherapists are ideally positioned to deliver physical activity (PA) promotion for both primary and secondary prevention of non-communicable diseases (NCDs) [1]. They have training and experience in educating clients and in prescribing PA programs for a range of NCDs, such as cardiovascular conditions and diabetes [1-5]. Physiotherapists often work with individuals over a period of weeks and months, providing them with the opportunity to follow-up on behaviour change strategies [1]. Despite this, there is little evidence of PA promotion by physiotherapists globally [6].

\footnotetext{
* Correspondence: Nicole.Freene@canberra.edu.au

Faculty of Health, University of Canberra, Canberra 2601, Australia
}

Physiotherapists around the world perceive that PA promotion is part of their role, with $50-99 \%$ of physiotherapists from Australia, Belgium, Brazil, Ireland and Nigeria agreeing this is part of their normal clinical work [5, 711]. A high proportion of physiotherapists report they are confident delivering general PA advice (90-97\%) [5, 7, 10]. However, there is some evidence that physiotherapists may feel less confident promoting PA to individuals with specific health conditions, such as individuals with respiratory and cardiovascular conditions [11]. Lack of consultation time is the most commonly perceived barrier for PA promotion $[5,9,10,12]$. In contrast to this, physiotherapists worldwide agree that brief education and advice is the most feasible option for PA promotion $[5,7,9,10,12]$.

Reported frequency of PA promotion amongst physiotherapists is fair, with $36-54 \%$ of physiotherapists in 
Australia and Nigeria promoting PA beyond therapeutic exercise to 10 or more patients per month $[5,10]$. Additionally, knowledge of the PA guidelines appears to be poor. Shirley et al. (2010) found that only one third of physiotherapists in New South Wales (NSW), Australia were aware of the Australian PA guidelines. Physiotherapists in Ireland and Belgium were found to have slightly better knowledge of their countries' PA guidelines (51-53\%) [7, 8]. Studies have found that PA promotion by physiotherapists can increase PA levels and reduce sedentary behaviour in the short (12 weeks) and long-term (2 years) [13, 14]. Yet, physiotherapists internationally do not seem to be taking advantage of opportunities and promoting PA to their patients [6].

One strategy to increase the population's PA levels is for health practitioners to incorporate PA promotion into routine healthcare [15]. To enable integration of PA promotion into routine physiotherapy care, it is essential to understand the current state of physiotherapists' PA promotion and knowledge across a number of settings, including private practices, hospitals and community settings. The aim of this study is to describe Australian physiotherapists' knowledge of the Australian physical activity and sedentary behaviour (PASB) guidelines, and factors that are associated with greater frequency of PA promotion.

\section{Methods}

\section{Study design}

A cross-sectional online survey was undertaken between January and March 2016. Using voluntary sampling, physiotherapists working in Australia were recruited through advertisements placed in physiotherapy-specific electronic publications and communications and via professional networks. Participants were included in the study if they self-reported they were currently practicing within Australia as a physiotherapist in any setting, including private practice, community health, public hospital or private hospital. To increase response rates, participants who completed the online questionnaire had an opportunity to win one of four AUS\$100 sports vouchers.

\section{Survey}

The online questionnaire was based on a previous questionnaire that had been used in physiotherapy and General Practice populations $[5,16]$. Minor adaptations were made to make it applicable to all settings, with the questionnaire taking approximately $10 \mathrm{~min}$ to complete. Participants were asked about their PA promotion practices, perceived role in PA promotion, barriers to promotion, feasibility of different promotion strategies, their knowledge of the PA public health messages and their personal PA levels. Most items were scored using a five-point Likert scale. The questionnaire also included general demographic questions, such as age, gender and details of the participant's work (average number of patients seen each week, number of years in practice, usual number of hours worked each week, workplace postal code and the type of practice). To facilitate analysis and reporting, each of the multiple response option variables were later transformed into a binary variable. For example, agree (combining the 2 'agree' options) versus disagree (combining 'neutral' with the 2 'disagree' options). Finally, participants were asked if they were aware of Australia's PASB Guidelines for Adults (18-64 years) [17] and, if so, to describe these. Each description was assessed for accuracy using a four-component scoring system. The four components of the guidelines assessed were duration, intensity, resistance exercise and minimising sedentary behaviour. To achieve a complete correct answer participants must have mentioned all four components according to the Australian PASB guidelines for Adults (18-64 years), that is, accumulate 150 to 300 min of moderate intensity physical activity or 75 to $150 \mathrm{~min}$ of vigorous intensity physical activity or a combination of both each week; muscle strengthening exercise at least 2 days per week; and minimise time spent in prolonged sitting [17].

\section{Sample size}

Sample size was based on the total number of registered physiotherapists in Australia in March $2015(n=27,370)$ [18]. Using an online survey sample size calculator, with a confidence interval of $95 \%$ and a $5 \%$ margin of error, the sample size required was 379 .

\section{Data analysis}

Descriptive analyses were completed. Responses of physiotherapists who more frequently counselled patients to increase their PA levels (beyond therapeutic exercise) were compared to those who less frequently counselled patients to determine factors that are associated with greater frequency of PA promotion. This was achieved by dividing the total sample into two groups, 'counselled $<10$ patients per month (less often)' versus 'counselled $\geq 10$ patients per month (more often)' [5, 10]. Associations between all variables were assessed using Spearman's rho. Logistic regression analysis with manual backward stepwise elimination was utilized, commencing with all potential predictor variables to identify the most parsimonious model for predicting counselling patients more often compared to counselling patients less often to have a more PA lifestyle. The criterion of $p<0.05$ was used to determine which variables were retained. The model was assessed for goodness of fit using the Hosmer-Lemeshow chi-square test and an area under the receiver operator characteristic (ROC) curve. All quantitative analyses were conducted using the Statistical Package for Social Sciences (SPSS) version 22. Significance level was set at $p<0.05$. 


\section{Results}

A total of 257 Australian physiotherapists completed the survey (Table 1). The majority of participants were female and one third were less than 35 years of age. Nearly half of participants worked in private practice and almost one quarter worked in public hospitals. Of the 29 participants who reported 'other' kinds of practice, most reported working in a mix of practices, aged care or rehabilitation settings. Complete data sets were found in $98 \%$ of cases.

Only one half of participants reported promoting PA beyond therapeutic exercise to 10 or more patients per month (Table 1). Ten percent of those who reported being aware of the Australian PASB guidelines for Adults (18-64 years) were able to accurately state all four components of the guidelines (Fig. 1). The majority of participants were able to accurately state the duration and intensity components but only one quarter of participants included the resistance or sedentary behaviour components in their responses.

Participants' knowledge of the Australian public health messages varied (Table 2). The majority of participants agreed that several short walks of 10 min on most days is better than one round of golf per week for good health. Approximately half of participants agreed that generally being more active each day is enough PA to

Table 1 Participant characteristics and characteristics of all registered physiotherapists in Australia

\begin{tabular}{|c|c|c|}
\hline Characteristic & Participants $(n=257)$ & $\begin{array}{l}\text { All registered Physiotherapists } \\
\text { in Australia }(n=28,669)^{\mathrm{a}}\end{array}$ \\
\hline \multicolumn{3}{|l|}{ Age (years), n (\%) } \\
\hline$<35$ & $93(36)$ & $13,641(48)$ \\
\hline $35-44$ & $48(19)$ & $6638(23)$ \\
\hline $45-54$ & $68(26)$ & $4557(16)$ \\
\hline$>54$ & $48(19)$ & $3833(13)$ \\
\hline \multicolumn{3}{|l|}{ Gender, n (\%) } \\
\hline Male & $57(22)$ & $9142(31)$ \\
\hline Female & $200(78)$ & $19,527(68)$ \\
\hline \multicolumn{3}{|l|}{ Kind of practice, n (\%) } \\
\hline Private practice & $114(44)$ & - \\
\hline Community health & $39(15)$ & - \\
\hline Public hospital & $62(24)$ & - \\
\hline Private hospital & $13(5)$ & - \\
\hline Other & $29(11)$ & - \\
\hline Number of years in practice, mean (SD) & $18.1(12)$ & - \\
\hline Average number of patients seen per week, mean (SD) & $41.8(32)$ & - \\
\hline Usual number of hours worked per week, mean (SD) & $31.6(13)$ & - \\
\hline \multicolumn{3}{|l|}{ Australian workplace postcode, n (\%) } \\
\hline $\mathrm{ACT}$ & $39(15)$ & $540(2)$ \\
\hline NSW & $59(23)$ & $8352(29)$ \\
\hline VIC & $62(24)$ & $7026(25)$ \\
\hline QLD & $42(17)$ & $5299(19)$ \\
\hline SA & $26(10)$ & $2283(8)$ \\
\hline WA & $27(11)$ & $3454(12)$ \\
\hline TAS & $0(0)$ & $448(2)$ \\
\hline NT & $0(0)$ & $165(1)$ \\
\hline \multicolumn{3}{|l|}{ Encouraged a physically active lifestyle } \\
\hline$\geq 10$ patients in the last month, $\mathrm{n}(\%)$ & $142(55)$ & - \\
\hline $\begin{array}{l}\text { How physically active do you think you are currently } \\
\text { compared with other Australians of your sex and age? } \\
\text { (agree = more active), n (\%) }\end{array}$ & $203(79)$ & - \\
\hline
\end{tabular}

- Data unavailable for total population of registered Physiotherapists in Australia

${ }^{\text {a }}$ hysiotherapy Board of Australia Registrant Data, March 2015 [18] 


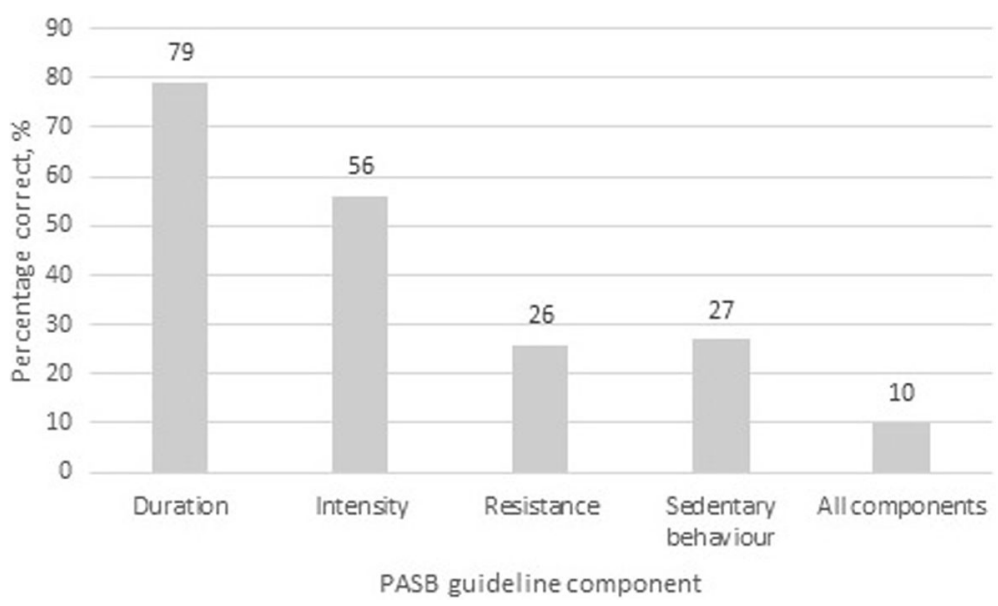

Fig. 1 Knowledge of the Australian Physical Activity and Sedentary Behaviour (PASB) guidelines among Australian physiotherapists

Table 2 Australian physiotherapists' knowledge, role perception, confidence, feasibility and barriers to physical activity promotion

\begin{tabular}{|c|c|}
\hline Variable $(n=257)$ & n Agree (\%) \\
\hline Aware of the Australian PASB guidelines & $168(65)$ \\
\hline \multicolumn{2}{|l|}{ Knowledge of PA message } \\
\hline Taking the stairs at work and generally being more active each day is enough PA to improve health & $138(54)$ \\
\hline Half an hour of walking on most days is all the exercise that is needed for good health & $111(43)$ \\
\hline Exercise that is good for health must make you puff and pant & $82(32)$ \\
\hline Several short walks of 10 min each on most days is better than one round of golf per week for good health & $201(78)$ \\
\hline \multicolumn{2}{|l|}{ Health Professionals Role } \\
\hline Discussing the benefits of a physically active lifestyle with patients is part of the health professionals role & $254(98.8)$ \\
\hline Suggesting to patients ways to increase daily PA is part of the health professionals role & $253(98.4)$ \\
\hline Health professionals should be physically active to act as a role model for their patients & $250(97.3)$ \\
\hline \multicolumn{2}{|l|}{ Confidence in giving PA message } \\
\hline I would feel confident in giving general advice to patients on a physically active lifestyle & $245(95.3)$ \\
\hline I would feel confident in suggesting specific physical activity & $239(93.0)$ \\
\hline \multicolumn{2}{|l|}{ Feasibility of PA promotion strategies } \\
\hline Brief counselling integrated into regular consultations & $241(93.8)$ \\
\hline Separate one-on-one consultations & $135(52.5)$ \\
\hline Group sessions & $173(67.3)$ \\
\hline Distribution of resources (such as brochures) & $240(93.4)$ \\
\hline \multicolumn{2}{|l|}{ Barriers to PA promotion } \\
\hline Lack of time & $35(13.6)$ \\
\hline Lack of counselling skills & $16(6.2)$ \\
\hline Lack of remuneration for promoting PA & $14(5.4)$ \\
\hline Lack of interest in promoting PA & $3(1.2)$ \\
\hline Feeling it would not change the patient's behaviour & $24(9.3)$ \\
\hline Feeling it would not be beneficial for the patient & $2(0.8)$ \\
\hline Other & $47(18.3)$ \\
\hline
\end{tabular}

PA physical activity 
improve health. Less than half of participants agreed that half an hour of walking on most days is all the exercise needed for good health; and that exercise must make you puff and pant to be good for health.

The majority of participants agreed that PA promotion is part of the physiotherapist's role and felt confident giving both general and specific PA advice to patients (Table 2). Overall, participants perceived few barriers to promotion (Table 2). 'Other' barriers were the most frequently reported, followed by lack of time. The most common 'other' barrier was PA promotion being inappropriate with some patients (e.g. low level of cognition, bed bound, acute unstable medical conditions), followed by feeling patients were not receptive. When considering feasibility of PA promotion strategies, brief counselling integrated into regular consultations was considered the most feasible strategy for promotion (Table 2).

Male participants were almost 3 times more likely to promote PA beyond therapeutic exercise to 10 or more patients per month than females. If participants agreed that separate one-on-one consultations were a feasible option for promotion they were 3 times more likely to promote PA to 10 or more patients per month. Table 3 details the results of the logistic regression modelling for factors associated with frequency of PA promotion by Australian physiotherapists. Participants who reported lack of counselling skills as a barrier to promotion were $83 \%$ less likely to promote PA to 10 or more patients per month. Those who reported feeling it wouldn't change the patient's behaviour were $73 \%$ less likely to promote PA to 10 or more patients per month. Treating a higher average number of patients per week was also a significant predictor of increased promotion frequency but number of hours worked per week was not retained in the model. The model demonstrated a good fit to the data and explained $33.2 \%$ of the variability.

\section{Discussion}

Australian physiotherapists have poor knowledge of the Australian PASB guidelines. Yet, the majority of participants felt confident promoting PA and agreed that PA promotion is part of their role, with half the participants promoting PA beyond therapeutic exercise to 10 or more patients per month. To our knowledge, this study is the first to find an association between gender and frequency of PA promotion, with male physiotherapists nearly three times more likely than females to promote PA to 10 or more patients per month, regardless of the number of hours worked per week. This finding may have important practical implications, with nearly $70 \%$ of Australian physiotherapists being female [18]. It is possible that this finding reflects a genuine disparity between male and female physiotherapists' PA promotion behaviours, or alternatively may reflect a gender discrepancy in the self-reporting of behaviour. A recent survey of physiotherapists in Nigeria, found that female physiotherapists were assessing the PA levels of their patients more frequently than males [9]. This is the only other study to identify a link between gender and PA promotion by physiotherapists and, as it explored PA assessment rather than promotion, it is difficult to compare these results with those of our study. Future studies in this area should specifically explore gender factors to ascertain whether this relationship between PA promotion and gender is consistent across different samples.

Few studies have explored physiotherapists' knowledge of the current PA guidelines. In 2010, Shirley et al. found that only one third of physiotherapists in NSW Australia were aware of the Australian PA guidelines. However, it was unclear if, and how, this study assessed the accuracy of participants' responses when they were asked to describe the PA guidelines. In Ireland, 51\% of physiotherapists were able to accurately recall the Irish PA guidelines [7]. A recent study of Belgian physiotherapists, assessing

Table 3 Logistic regression model for factors associated with frequency of physical activity promotion beyond therapeutic exercise by Australian physiotherapists

\begin{tabular}{|c|c|c|}
\hline Variable & Odds ratio & $95 \% \mathrm{Cl}$ \\
\hline \multicolumn{3}{|l|}{ Barriers to promotion $^{a}$} \\
\hline Lack of counselling skills & $0.165^{*}$ & $0.038-0.710$ \\
\hline Feeling it would not change the patient's behaviour & $0.271^{*}$ & $0.093-0.795$ \\
\hline \multicolumn{3}{|l|}{ Feasible strategies for promotion ${ }^{a}$} \\
\hline Separate one-on-one consultations & $3.228^{* *}$ & $1.813-5.749$ \\
\hline Average number of patients seen per week & $1.028^{* *}$ & $1.014-1.043$ \\
\hline Gender ${ }^{b}$ & $2.679^{*}$ & $1.250-5.740$ \\
\hline Hosmer-Lemeshow goodness of fit $(p)$ & 0.593 & \\
\hline Nagalkerke R Square & 0.332 & \\
\hline Area under ROC curve & 0.803 & \\
\hline
\end{tabular}

${ }^{a}$ reference agree ${ }^{b}$ reference male ${ }^{*} p<0.05 * * 0.001$ 
knowledge of the Belgian PA guidelines using a scoring system similar to that used here, reported that $53 \%$ of Belgian participants correctly mentioned 3 out of 4 components of the Belgian PA guidelines, with no report of the percentage of participants who could accurately state each individual component [8]. Whilst we found that the knowledge of the PA guidelines was much lower (10\%) relative to previous studies, others did not require participants to include the recommendations for resistance exercise and/or sedentary behaviour in their responses. This is likely due to the sedentary behaviour component of the guidelines recently being added in Australia [19] and not yet being included in the Irish or Belgian guidelines [20, 21]. Nonetheless, Australian physiotherapists' knowledge of the guidelines appears to be poor overall.

In addition to poor knowledge of the PA guidelines, participants' knowledge of Australian public health messages relating to PA was limited. Only half of the participants agreed that generally being more active each day is enough PA to improve health. This may be due to physiotherapists believing that a larger amount of PA is needed for good health. This may also indicate that physiotherapists lack knowledge of the significant health benefits that can occur with small amounts of PA, such as half an hour of brisk walking on most days of the week [19]. Furthermore, it is possible that if physiotherapists don't agree with these public health messages they may not promote them to patients, or they may advise patients that a larger amount of PA is necessary to achieve good health, making increasing PA levels seem less achievable for patients. One third of participants agreed that exercise that is good for health must make you puff and pant. This may also indicate a limited understanding that at least moderate intensity PA is recommended to achieve health benefits, or it may indicate a poor understanding of the definition of moderate intensity $[17,22,23]$.

Regardless of the reasons why their knowledge was limited, our findings indicate that Australian physiotherapists require further education on all components of the Australian PASB guidelines, with a particular focus on resistance activities and sedentary behaviour. A systematic review of factors influencing health professionals PA promotion found that decreased PA awareness and knowledge results in decreased PA promotion [24]. Thus, PA awareness and knowledge appears to be essential for PA promotion, and this lack of PA knowledge is potentially rectifiable through education [25].

In our study, physiotherapists who lacked counselling skills, or felt that PA promotion wouldn't change the patient's behaviour and didn't see one-on-one consultations as feasible options for PA promotion, were significantly less likely to promote PA. Previous studies have shown similar results $[5,24]$. To reduce these barriers to PA promotion, physiotherapists may require further education and training in PA counselling and behaviour change strategies. However, it is important to consider that only $6 \%$ of all participants reported lack of counselling skills as a barrier to promotion. While this is an important area to address, it is not a common barrier reported by Australian physiotherapists.

The findings for PA promotion role perception, barriers, feasibility and confidence are similar to other studies conducted with physiotherapists around the world [5, 7-11]. Australian physiotherapists strongly agreed that PA promotion was part of their role and felt very confident that they could provide both general and specific PA advice to patients. This is in contrast to Mohan et al. (2012) that found Irish senior physiotherapists were less confident giving specific advice to individuals with respiratory and cardiovascular conditions. Importantly, here we found confidence was not significantly associated with frequency of promotion. Thus, confidence may not translate into PA promotion practice.

Barriers to PA promotion were few. 'Other' barriers, such as feeling it wouldn't be appropriate with some patients, alongside lack of time, were the most frequently cited. While PA promotion may be inappropriate with some patients, such as those who are bed-bound or those with acute medical conditions, PA promotion can be adapted to be safe and appropriate for those with cognitive disorders and comorbidities [26-31]. Brief counselling integrated into regular consultations was found to be the most feasible option for PA promotion, which has also been found in previous studies $[5,10]$. There is evidence that brief PA advice in primary care settings is effective [32]. Considering this, incorporating brief PA advice into routine physiotherapy consultations may be an achievable and successful PA promotion strategy.

Limitations to this study include a limited sample size and only offering the survey online, which may have limited responses from those that did not have access to an electronic device. Selection bias may have also occurred due to voluntary sampling, with the survey being promoted more widely in the area where the research team was located, and physiotherapists more interested in PA potentially more likely to complete the survey. There is also the potential for recall and social desirability bias. Physiotherapists may have over or under-estimated the number of patients they promoted PA to during the past month, and they may have inaccurately estimated their personal level of PA.

\section{Conclusion}

Australian physiotherapists perceive PA promotion to be part of their role and feel confident promoting PA to their patients. Despite this, PA knowledge amongst Australian physiotherapists is poor. Training in brief PA counselling 
and behaviour change for practicing physiotherapists is indicated, particularly targeting female physiotherapists. If physiotherapists increase their PA knowledge, improve their PA counselling skills and take advantage of opportunities within routine physiotherapy consultations, they have the potential to increase PA levels of the Australian population.

\section{Abbreviations}

NCDs: non-communicable diseases; NSW: New South Wales; PA: physical activity; PASB: physical activity and sedentary behaviour

\section{Acknowledgments}

We are grateful to all the Australian physiotherapists who completed this survey. We would also like to acknowledge Dr. Danny Hills for his statistical support.

\section{Ethics and consent to participate}

Ethical approval was obtained from the University of Canberra Human Research Ethics Committee in October 2015 (HREC 15-207).

Study information including the project aim, data storage and details regarding participant involvement, confidentiality and anonymity were included at the start of the online survey. Participants were advised that after reading this information, by clicking 'continue' they consented to take part in the online survey.

\section{Funding}

This study was supported by a University of Canberra Faculty of Health Research Funding Grant

\section{Availability of data and materials}

The datasets used and/or analysed during the current study are available from the corresponding author on reasonable request.

\section{Authors' contributions}

SC, NF, BB contributed to the design of the study. SC collected the data. NF and SC analysed the data. SC, NF, BB interpreted the data. NF drafted the manuscript. All authors contributed to, read and approved the final manuscript.

\section{Consent for publication}

Not applicable.

\section{Competing interests}

The authors declare that they have no competing interests.

\section{Publisher's Note}

Springer Nature remains neutral with regard to jurisdictional claims in published maps and institutional affiliations.

\section{Received: 14 September 2017 Accepted: 20 November 2017}

\section{Published online: 29 November 2017}

\section{References}

1. Dean E, Dornelas de Andrade A, O'Donoghue G, Skinner M, Umereh G, Beenan P, Cleaver S, Afzalzada D: The Second Physical Therapy Summit on Global Health: developing an action plan to promote health in daily practice and reduce the burden of non-communnicable diseases. Physiother Theory Prac 2013, Early Online:1-15.

2. Florindo A, Mielke G, Gomes G, Ramos L, Bracco M, Parra D, Hallal P. Physical activity counselling in primary health care in Brazil: a national study on prevalence and associated factors. BMC Public Health. 2013;13(1):794-84.

3. Alexander J, Bambury E, Mendoza A, Reynolds J, Veronneau R, Dean E. Health education strategies used by physical therapists to promote behaviour change in people with lifestyle-related conditions: a systematic review. Hong Kong Physiotherapy Journal. 2012;30(2):57-75.

4. You L, Sadler G, Majumdar S, Burnett D, Evans C. Physiotherapists' perceptions of their role in the rehabilitation Management of Individuals with obesity. Physiother Can. 2012;64(2):168-75.
5. Shirley D, Van der Ploeg HP, Bauman AE. Physical activity promotion in the physical therapy setting: perspectives from practitioners and students. Phys Ther. 2010;90(9):1311-22.

6. Lowe A, Gee M, McLean S, Littlewood C, Lindsay C, Everett S. Physical activity promotion in physiotherapy practice: a systematic scoping review of a decade of literature. Br J Sports Med. 2016; EPub 21 December 2016

7. Barrett EM, Darker CD, Hussey J. Promotion of physical activity in primary care: knowledge and practice of general practitioners and physiotherapists. Journal of Public Health. 2013;21(1):63-9.

8. Mouton A, Mugnier B, Demoulin C, Cloes M. Physical therapists' knowledge, attitudes, and beliefs about physical activity: a prerequisite to their role in physical activity promotion? Journal of Physical Therapy Education. 2014; 28(3):120-7.

9. Abaraogu UO, Edeonuh JC, Frantz J. Promoting physical activity and exercise in daily practice: current practices, barriers, and training needs of physiotherapists in eastern Nigeria. Physiother Can. 2016;68(1):37-45.

10. Aweto HA, Oligbo CN, Fapojuwo OA, Olawale OA. Knowledge, attitude and practice of physiotherapists towards promotion of physically active lifestyles in patient management. BMC Health Serv Res. 2013;13(1):1-8.

11. Mohan N, Collins E, Cusack T, O'Donoghue G. Physical activity and exercise prescription: senior physiotherapists' knowledge, attitudes and beliefs. Physiother Pract Res. 2012;33(2):71-80.

12. Frantz JM, Ngambare R. Physical activity and health promotion strategies among physiotherapists in Rwanda. Afr Health Sci. 2013;13(1):17-23.

13. Freene $\mathrm{N}$, Waddington $\mathrm{G}$, Davey $\mathrm{R}$, Cochrane $\mathrm{T}$. Longitudinal comparison of a physiotherapist-led, home-based and group-based program for increasing physical activity in community-dwelling middle-aged adults. Aust J Prim Health. 2015;21(2):189-96.

14. Holm I, Tveter AT, Moseng T, Dagfinrud H. Does outpatient physical therapy with the aim of improving health-related physical fitness influence the level of physical activity in patients with long-term musculoskeletal conditions? Physiotherapy. 2015;101(3):273-8.

15. National Heart Foundation of Australia: Blueprint for an active Australia. 2nd edn. Melbourne: National Heart Foundation of Australia; 2014. https://www. heartfoundation.org.au/images/uploads/publications/Blueprint-for-an-activeAustralia-second-edition.pdf.

16. van der Ploeg HP, Smith BJ, Stubbs T, Vita P, Holford R, Bauman AE. Physical activity promotion: are GPs getting the message? Aust Fam Physician. 2007; 36(10):871-4.

17. The Department of Health. Australia's physical activity and sedentary behaviour guidelines. Canberra: Australian Government Department of Health; 2014. http://www.health.gov.au/internet/main/publishing.nsf/ content/health-pubhlth-strateg-phys-act-guidelines

18. Physiotherapy Board of Australia: physiotherapy registrant data. Melbourne VIC: AHPRA. March 2015:2015. http://www.physiotherapyboard.gov.au/ About/Statistics.aspx

19. Brown W, Bauman A, Bull F, Burton N: Development of evidence-based physical activity recommendations for adults (18-64 years). Department of Health; 2012. http:/www.health.gov.au/internet/main/publishing.nsf/Content/health-pubhlthstrateg-phys-act-guidelines/\$File/DEB-PAR-Adults-18-64years.pdf.

20. The Department of Health and Children, The Health Service Executive: The National Guidelines on Physical Activity for Ireland. Ireland; 2009.

21. Kahlmeier S, Wijnhoven T, Alpiger P, Schweizer C, Breda J, Martin B. Nationa physical activity recommendations: systematic overview and analysis of the situation in European countries. BMC Public Health. 2015;15(1):133.

22. World Health Organisation: Global Recommendations on Physical Activity for Health; 2010: 9-11, 29-33. http://www.who.int/dietphysicalactivity/ factsheet_recommendations/en/

23. Manson JE, Greenland P, LaCroix AZ, Stefanick ML, Mouton CP, Oberman A Perri MG, Sheps DS, Pettinger MB, Siscovick DS. Walking compared with vigorous exercise for the prevention of cardiovascular events in women. $\mathrm{N}$ Engl J Med. 2002;347(10):716-25

24. Huijg J, Gebhardt W, Verheijden M, Zouwe N, Vries J, Middelkoop B, Crone M. Factors influencing primary health care Professionals' physical activity promotion behaviors: a systematic review. Int J Behav Med. 2015;22(1):32-50.

25. Johnson ST, Bates H, Fitzpatrick J, Marshall JD, Bell RC, McCargar L. Promotion of physical activity by Canadian registered dietitians in daily practice. J Hum Nut Diet. 2007;20(1):37-40.

26. Vreugdenhil A, Cannell J, Davies A, Razay G. A community-based exercise programme to improve functional ability in people with Alzheimer's disease: a randomized controlled trial. Scand J Caring Sci. 2012;26(1):12-9. 
27. Devine JM, Zafonte RD. Physical exercise and cognitive recovery in acquired brain injury: a review of the literature. PM\&R. 2009;1(6):560-75.

28. National Heart Foundation of Australia: Physical activity in patients with cardiovascular disease: management algorithm and information for general practice. National Heart Foundation of Australia; 2006. https://www. heartfoundation.org.au/images/uploads/publications/physical-activity-inpatients-with-cvd-management-algorithm.pdf

29. Burr JF, Shephard RJ, Zehr EP. Physical activity after stroke and spinal cord injury: evidence-based recommendations on clearance for physical activity and exercise. Can Fam Physician. 2012;58(11):1236-9.

30. Burr JF, Davidson W, Shephard RJ, Eves N. Physical activity in chronic respiratory conditions: assessing risks for physical activity clearance and prescription. Can Fam Physician. 2012;58(7):761-4.

31. Colberg SR, Sigal RJ, Fernhall B, Regensteiner JG, Blissmer BJ, Rubin RR, Chasan-Taber L, Albright AL, Braun B. Exercise and type 2 diabetes: the American College of Sports Medicine and the American Diabetes Association: joint position statement. Diabetes Care. 2010;33(12):e147-67.

32. Orrow G, Kinmonth A-L, Sanderson S, Sutton S: Effectiveness of physical activity promotion based in primary care: systematic review and metaanalysis of randomised controlled trials. (BMJ Clin ResEd) 2012, 344: e1389-e1389.

\section{Submit your next manuscript to BioMed Central} and we will help you at every step:

- We accept pre-submission inquiries

- Our selector tool helps you to find the most relevant journal

- We provide round the clock customer support

- Convenient online submission

- Thorough peer review

- Inclusion in PubMed and all major indexing services

- Maximum visibility for your research

Submit your manuscript at www.biomedcentral.com/submit 